\title{
Mice Lacking Free Fatty Acid Receptor 1 (GPR40/FFAR1) are Protected Against Conjugated Linoleic Acid-Induced Fatty Liver but Develop Inflammation and Insulin Resistance in the Brain
}

\author{
Tina Sartorius ${ }^{a, b, c} \quad$ Andrea Drescher ${ }^{a}$ Madhura Panse ${ }^{a}$ Petr Lastovickad \\ Andreas Peter ${ }^{a}$ Cora Weigert ${ }^{a, b, c}$ Evi Kostenis ${ }^{e}$ Susanne Ullrich ${ }^{a, b}$ \\ Hans-Ulrich Häring ${ }^{a, b, c}$
}

aDepartment of Internal Medicine, Division of Endocrinology, Diabetology, Vascular Disease, Nephrology and Clinical Chemistry, Member of the German Center for Diabetes Research (DZD), University of Tuebingen, Germany, bGerman Center for Diabetes Research (DZD), Tuebingen, Germany, Institute for Diabetes Research and Metabolic Diseases of the Helmholtz Center Munich at the University of Tuebingen (IDM), Tuebingen, Germany, dUniversity of Pardubice, Faculty of Chemical Technology, Department of Biological and Biochemical Sciences, Pardubice, Czech Republic, eUniversity of Bonn, Institute of Pharmaceutical Biology, Bonn, Germany

\section{Key Words}

$\mathrm{CLA} \cdot$ Electrocorticography $\bullet \mathrm{Ffar1}^{-1}$ mouse $-\mathrm{FFAR1} \cdot \mathrm{GPR} 40 \cdot$ Insulin resistance $\bullet$ Fatty liver $\bullet$ Brain insulin resistance $\cdot$ Brain inflammation $\bullet$ Radiotelemetry

\begin{abstract}
Background/Aims: Conjugated linoleic acids (CLAs) affect body fat distribution, induce insulin resistance and stimulate insulin secretion. The latter effect is mediated through the free fatty acid receptor-1 (GPR40/FFAR1). This study examines whether GPR40/FFAR1 interacts with tissue specific metabolic changes induced by CLAs. Methods and Results: After chronic application of CLAs C57BL/6J wild type (WT) and GPR40/FFAR1 (Ffar1 ${ }^{-/}$) knockout mice developed insulin resistance. Although CLAs accumulated in liver up to 46-fold genotypeindependently, hepatic triglycerides augmented only in WT mice. This triglyceride deposition was not associated with increased inflammation. In contrast, in brain of CLA fed $\mathrm{Ffarl}^{-1}$ mice mRNA levels of TNF- $\alpha$ were 2-fold higher than in brain of WT mice although CLAs accumulated genotype-independently in brain up to 4 -fold. Concomitantly, Ffar $1^{-1-}$ mice did not respond to intracerebroventricular (i.c.v.) insulin injection with an increase in cortical activity while WT mice reacted as assessed by radiotelemetric electrocorticography (ECoG) measurements. In vitro incubation of primary murine astrocytes confirmed that CLAs stimulate

Dr. Tina Sartorius

University of Tuebingen, Department of Internal Medicine IV

KARGER 125 
neuronal inflammation independent of GPR40/FFAR1. Conclusion: This study discloses that GPR40/FFAR1 indirectly modulates organ-specific effects of CLAs: the expression of functional GPR40/FFAR1 counteracts CLA-induced inflammation and insulin resistance in the brain, but favors the development of fatty liver.

Copyright $\odot 2015$ S. Karger AG, Basel

\section{Introduction}

Conjugated linoleic acids (CLAs) are geometric isomers of linoleic acid (C18:2n-6) and occur naturally in two isomers, the cis-9,trans-11 $(c 9, t 11)$ and the trans-10,cis-12 $(t 10, c 12)$. They are widely used as food additives since they reduce adipose tissue and increase muscle mass $[1,2]$. It has been suggested that the decrease in body fat is predominantly mediated by the $t 10, c 12$-CLA isomer and involves an apoptotic mechanism linked to an increased TNF- $\alpha$ production [3]. Additionally, the $t 10, c 12$ - but not the $c 9, t 11$-CLA isomer inhibits SCD1, an effect which may contribute to the reduction of fat deposits [4, 5]. Beside these rather beneficial effects, the intake of CLAs also results in adverse effects such as worsening peripheral insulin resistance and increasing the risk of developing diabetes. These detrimental effects are again caused mainly by the $t 10, c 12$-CLA isomer [6].

Previously, we described that both CLA isomers specifically activate the cell membrane free fatty acid receptor 1 (GPR40/FFAR1) [7]. GPR40/FFAR1 is expressed in $\beta$-cells where the receptor transmits stimulation of insulin secretion by long and medium chain fatty acids as well as by CLAs $[8,9]$. In intestinal K- and L-cells GPR40/FFAR1 is involved in the production of regulatory peptides, especially GLP-1 and GIP, which are important regulators of glucose metabolism [10]. Whether the expression of GPR40/FFAR1 is restricted to these specialized endocrine cells is still a matter of debate due to the limited availability of specific tools for receptor detection [11]. In particular, the expression of GPR40/FFAR1 in rodent brain may be restricted to defined areas with a marginal expression in comparison to the abundance of mRNA found in $\beta$-cells [12]. Remarkably, in human brain an omnipresent expression of GPR40/FFAR1 receptors is prominent and comparable to that in islets [8, 13]. A similar high expression of GPR40/FFAR1 is found in macaque brain where it may play an important role in the regulation of certain neurological functions such as hippocampal neurogenesis and memory $[14,15]$.

An incorporation and metabolism of CLAs in brain tissue of rodents and neonatal pigs has been described after acute or short-term treatment with these isomers [16-18]. Direct i.c.v. application of CLAs affected appetite regulation as they decreased the expression of neuropeptide Y (NPY) and agouti-related protein (AgRP) in rat's brain [19]. Thus, CLAs may directly influence brain function.

The impact of GPR40/FFAR1 activity on brain function remains unknown. Most intriguingly, while GPR40/FFAR1 deficiency may protect from fatty liver and receptor antagonists are discussed as therapeutic tools for the prevention of liver steatosis, agonists are under evaluation as therapeutic tool for the treatment of insulin deficiency in type 2 diabetic patients [20,21]. The liver, however, does not express the receptor suggesting that the adverse effect of receptor deficiency on hepatic steatosis is indirectly mediated through organ crosstalk.

Conflicting results are published regarding the effects of high-fat diet (HFD) on metabolic homeostasis in mice lacking GPR40/FFAR1. While Steneberg et al. reported that GPR40/FFAR1 deficient animals are protected from obesity-induced hyperinsulinemia, hyperglycemia, and hepatic steatosis [20], Lan et al. found that the receptor does not protect from the negative effects of HFD feeding, like obesity, insulin resistance, and hepatic lipid accumulation [22]. To circumvent the fat overload of saturated fatty acids present in HFD, the present study was undertaken to explore the role of GPR40/FFAR1 on CLA-induced metabolic changes and organ-specific effects. The in vivo application of CLAs in a moderate dietary fat supplementation to WT and $\mathrm{Ffar}^{1 \%}$ mice was chosen for this purpose as this 


\section{Cellular Physiology Cell Physiol Biochem 2015;35:2272-2284 \begin{tabular}{l|l} 
and Biochemistry 10.1159/000374031 & $\begin{array}{l}\text { (c) 2015 S. Karger AG, Basel } \\
\text { Published online: April 13, } 2015\end{array}$ \\
\hline
\end{tabular} \\ Sartorius et al.: FFAR1-Mediated CLA Effects}

model enabled us to study direct effects of GPR40/FFAR1-stimulation as well as to decipher indirect effects exerted through organ crosstalk. Thus, the study aims to decipher the impact of GPR40/FFAR1 on fat redistribution induced by CLAs, i.e. on hepatic steatosis, and on CLAmediated changes in brain function.

\section{Materials and Methods}

Animals and chronic CLA treatment

C57BL/6J wild type (WT) and GPR40/FFAR1 knockout mice (Ffar1 ${ }^{-\%}$ ) littermates (6-10 week old, male and female), kindly provided by Novartis Pharma KG, Basel, Switzerland, were kept in a pathogen free facility. The animals were maintained on a $12 \mathrm{~h}$ light-dark cycle with free access to food (Ssniff ${ }^{\circledR} \mathrm{R} / \mathrm{M}-\mathrm{H}$, Soest, Germany), and water. The non-purified diet with moderate energy density (gross energy: 16.3 MJ/ $\mathrm{kg}$; metabolizable energy: $12.8 \mathrm{MJ} / \mathrm{kg}$ ) consisted of $19 \%$ crude protein, $3.3 \%$ crude fat, $4.9 \%$ crude fibre, $6.4 \%$ crude ash, $36.5 \%$ starch, and $4.7 \%$ sugar. Ffar ${ }^{-1}$ and WT mice were daily fed by gavage for 36 days with $0.45 \mathrm{~g} / \mathrm{kg}$ body weight Tonalin ${ }^{\circledR}$ solution containing $c 9, t 11$ - and $t 10, c 12$-CLA isomers in a $50: 50$ ratio (Cadion, Zirndorf, Germany). Sunflower oil (Thomy®, Nestlé Deutschland AG, Frankfurt/Main, Germany) was used as vehicle solution to attain an isocaloric load. It contained $11.5 \%$ saturated fatty acids, 23.9 $\%$ monounsaturated fatty acids, and $63.9 \%$ polyunsaturated fatty acids, whereat linoleic acid (C18:2) represented 63.6\%. Body weight and food intake were determined weekly. All animal procedures were approved by local government authorities for animal research according to the guidelines of laboratory animal care.

Glucose and insulin tolerance test

At day 30 of CLA treatment glucose tolerance (GTT) was assessed in overnight-fasted animals by an intraperitoneal (i.p.) administration of $2 \mathrm{~g} / \mathrm{kg} \alpha$-D-glucose, and blood samples were taken from the tail vein to determine blood glucose concentration after $0,15,30,60$, and $120 \mathrm{~min}$. Three days later insulin tolerance testing (ITT) was performed by injecting fed mice i.p. with $1 \mathrm{U} / \mathrm{kg}$ body weight of human insulin (Novo Nordisk, Bagsværd, Denmark) at 8 a.m., and blood samples were taken before and at 15, 30, and 60 min after injection. Blood glucose concentrations were determined using a Glucometer Elite (Bayer, USA).

\section{Measurements of electrocorticography (ECoG) by radiotelemetry}

Mice were subcutaneously implanted with a telemetry electrocorticography transmitter (DSI, St Paul, MN, USA) and a cannula for intracerebroventricular (i.c.v.) injection of insulin into the cerebrospinal fluid as previously described [23]. After chronic CLA treatment the mice underwent ECoG measurements for 4 days. The monitoring was continued after i.c.v. injection of insulin $(3.75 \mathrm{mU} / 5 \mu \mathrm{L})$ or control solution $(0.9 \% \mathrm{NaCl})$ and recording was continuously performed during $120 \mathrm{~min}$ post-injection. Using fast fourier transformation for theta $(4-8 \mathrm{~Hz})$ and alpha $\left(8-12 \mathrm{~Hz}\right.$ ) frequency bands, the power spectral density in $\mu \mathrm{V}^{2} / \mathrm{Hz}$ was calculated for ECoG measurement analysis and displayed as percentage change of control application (with $0 \%$ as baseline) to exclude inter-individual variation in baseline cortical ECoG activity. Mice which responded with a significant increase in cortical activity upon i.c.v. injection of insulin (compared to control i.c.v. application) were considered as insulin sensitive.

Cytokine measurement

Blood samples were withdrawn from the retro-orbital venous plexus of fasted mice under ketamine/ xylazine anesthesia at 8 a.m. of day 37 as terminal procedure. After centrifugation at $4^{\circ} \mathrm{C}$ plasma samples were stored at $-20^{\circ} \mathrm{C}$. Detection of cytokines (IL1- $\beta$, IL-6, and TNF- $\alpha$ ) was done by multiplex analysis using the Bio-Plex Pro Mouse Cytokine Group I Panel (23-plex panel, Z60000DRH1, Bio-Rad, Munich, Germany). All samples were diluted 1:2 and run in duplicate. Calculation was performed with the Luminex software (LX100 IS 2.3) and results were expressed as median fluorescence intensity of 100 micro spheres of each set.

\section{Semiquantitative PCR analysis}

Frozen brain, hypothalamus and liver tissue samples were homogenized in a TissueLyser (Qiagen, Hilden, Germany) and RNA was extracted with the RNeasy Tissue Kits (Qiagen). Cultured mouse primary 
Sartorius et al.: FFAR1-Mediated CLA Effects

Table 1. Primer sequences used for semiquantitative PCR. FFAR1, free fatty acid receptor 1; GAPDH, glyceraldehyde 3-phosphate dehydrogenase; IL-6, interleukin 6; RPS13, ribosomal protein S13; TNF- $\alpha$, tumor necrosis factor alpha

\begin{tabular}{llcll}
\hline Protein & Gene & Roche probe \# & Upstream primer & Downstream primer \\
\hline FFAR1 & Ffar1 & 50 & 5'-CATCACTCTGCCCCTGAAG-3' & 5'-AAGGCAAAGACTGGGCAGA-3' \\
RPS13 & Rps13 & 110 & 5'-TGCTCCCACCTAATTGGAAA-3' & 5'-CTTGTGCACACAACAGCATTT-3' \\
& & & & \\
TNF- $\alpha$ & Tnf & - & 5'-AAATGGCCTCCCTCTCATCA-3' & 5'-AGATAGCAAATCGGCTGACG-3' \\
GAPDH & Gapdh & - & 5'-AACGACCCCTTCATTGAC-3' & 5'-TCCACGACATACTCAGCAC-3' \\
IL-6 & Il6 & - & 5'-GATGCTACCAAACTGGATATAATC-3' & 5'-GGTCCTZAGCCACTCCTTCTGTG-3' \\
\hline
\end{tabular}

astrocytes were lysed in QIAzol ${ }^{\circledR}$ Lysis Reagent and RNA was prepared using QIAshredder ${ }^{\mathrm{TM}}$ and RNeasy Mini Kit (Qiagen). DNase-treated RNA samples $(1 \mu \mathrm{g})$ were subjected to cDNA synthesis using avianmyoblastosis virus (AVMV) reverse transcriptase (Roche, Mannheim, Germany). For detection of Ffar1 gene expression, a negative control (RNA) was subjected to amplification along with every cDNA sample by omitting reverse transcriptase. RNA from Min6 cells, which were kept under standard culture conditions (Dulbecco's modified Eagle's medium (DMEM) containing $4.5 \mathrm{~g} / \mathrm{L}$ glucose (Lonza, Brussels, Belgium) supplemented with 15\% heat-inactivated fetal bovine serum, $2 \mathrm{mM}$ L-glutamine, and $70 \mu \mathrm{M} \beta$-mercaptoethanol in humidified 5\% $\mathrm{CO}_{2}, 95 \%$ air at $37^{\circ} \mathrm{C}$ ), was used as positive control. PCR was performed using kits from Qiagen and Roche on Roche LightCycler Systems 1.5 or 480 and by using primers from Invitrogen (Darmstadt, Germany), TIB Molbiol (Berlin, Germany), and eurofins Genomics (Ebersberg, Germany). The amount of target gene mRNA was estimated relative to the house keeping gene (Rps13 or Gapdh). Sequences of all primers are listed in Table 1.

Determination of triglyceride and CLA isomer content from tissue biopsies

Tissue samples were homogenized in PBS containing 1\% Triton X-100 using a TissueLyser (Qiagen, Hilden, Germany). Triglyceride (TG) content was quantified in the homogenates using the ADVIA 1800 clinical chemistry analyzer (Siemens Healthcare Diagnostics, Eschborn, Germany). Using thin layer chromatography (TLC), the TG fraction was separated from other hepatic lipids in the homogenate. Concentrations of both CLA isomers in liver and brain tissue were measured by gas chromatography with a flame ionization detector as previously described [24].

\section{Primary astrocyte cultures}

Primary astrocytes were isolated from pups of 2 day-old WT mice as described previously [25] and cultured in DMEM containing $4.5 \mathrm{~g} / \mathrm{L}$ glucose (Lonza, Brussels, Belgium). After purification from oligodendrocytes, astrocytes were grown to confluence and cytosine- $\beta$-arabinofuranoside (Sigma-Aldrich, Taufkirchen, Germany) was then added to inhibit DNA replication. Cells were treated for $24 \mathrm{~h}$ with 100 $\mu \mathrm{mol} / \mathrm{L} c 9, t 11$ - or $t 10, c 12$-CLA isomer (dissolved at $100 \mathrm{mmol} / \mathrm{L}$ in ethanol) ,100 $\mu \mathrm{mol} / \mathrm{L}$ alpha-linoleic acid (dissolved at $100 \mathrm{mmol} / \mathrm{L}$ in ethanol), and with TUG-761 (10 $\mu \mathrm{mol} / \mathrm{L}$, dissolved in DMSO at $10 \mathrm{mmol} / \mathrm{L})$ as indicated [26].

\section{Statistical analysis}

Data are expressed as mean \pm SEM of the indicated number of experiments and analyzed using Origin 8.1 (Northhampton, MA, USA) software. Significance for all analyses was set to $P<0.05$. Body weight and blood glucose concentrations (total and percental) during GTT and ITT were analyzed with a two-way ANOVA, with the factors treatment (vehicle vs. CLA) and genotype (WT vs. Ffar 1\% mice). This automatically also tested for interaction effects between genotypes and treatment conditions (CLA-isomer concentrations and relative mRNA of TNF- $\alpha$ in liver, hypothalamus and brain tissue, and triglycerides in liver). Power of cortical activity after i.c.v. insulin injection was analyzed with one-way ANOVA, with the factor genotype. The Bonferroni multiple comparison procedure was used for post hoc testing. Relative mRNA of TNF- $\alpha$ and IL-6 within vehicle, TUG-761 or $\alpha$-LA groups was calculated using one-way ANOVA, with the factor CLAisomer, followed by Bonferroni's post hoc comparisons. To compare CLA-isomers to one another within animal, one-way ANOVA was applied. 
A

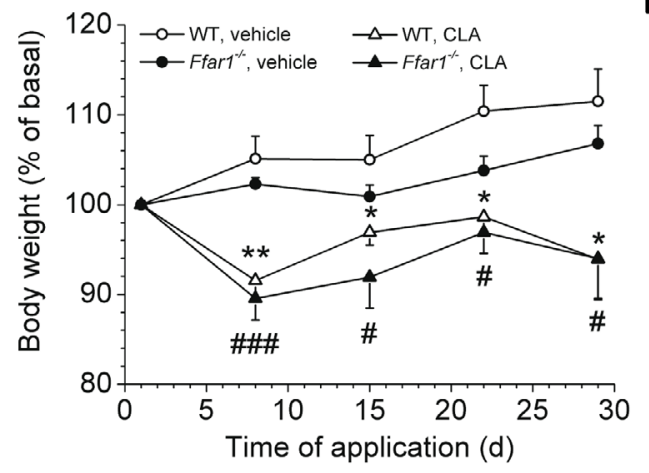

C

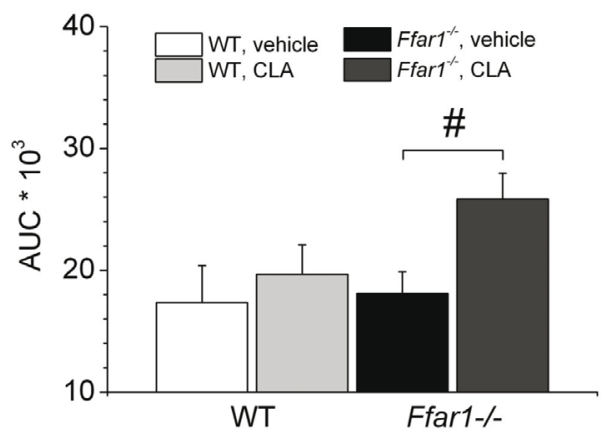

B

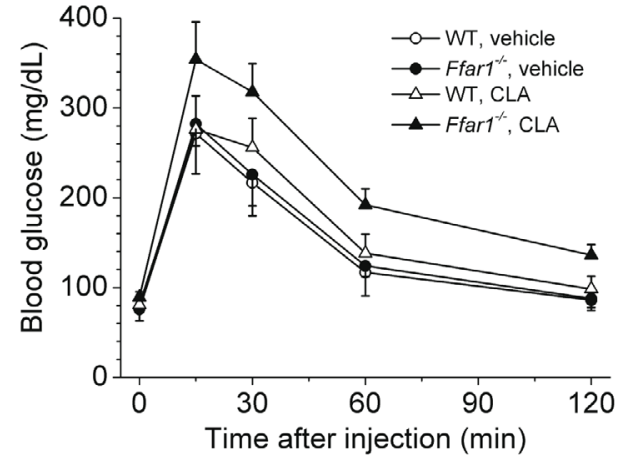

D

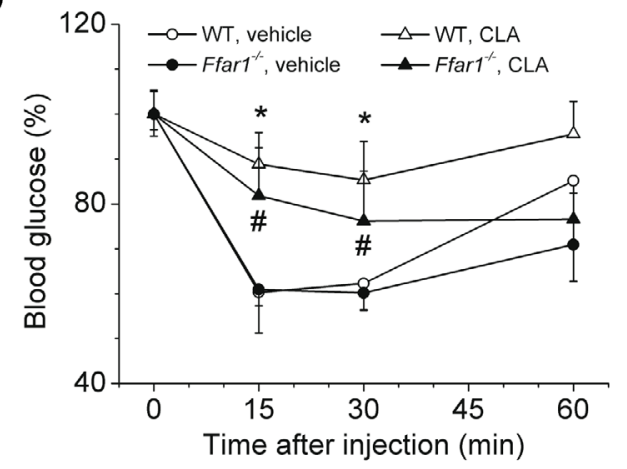

Fig. 1. GPR40/FFAR1 did not influence CLA-induced reduction of body weight and the development of insulin resistance in WT and Ffar $1^{-/}$mice. (A) Body weight changes over 29 day feeding period. (B) Blood glucose excursions during GTT. (C) Areas under the curves (AUC) from blood glucose concentration during glucose GTT. (D) Blood glucose concentrations (\% of baseline) after i.p. injection of insulin. Data are mean \pm SEM ( $n=3-5$ /group). *Different from sunflower oil-fed (vehicle) WT, $\mathrm{P}<0.05$; **different from sunflower oil-fed WT, $P<0.005$; \#different from sunflower oil-fed Ffar $1 \%$ mice, $P<0.05$; \#\#\#different from sunflower oil-fed Ffar ${ }^{\%}$ mice, $P<0.001$. CLAs, conjugated linoleic acids; Ffar $1 \%$, GPR40/FFAR1 knockout mice; GTT, glucose tolerance test, i.p., intraperitoneal; WT, wild-type.

\section{Results}

CLA ingestion reduced body weight, but induced insulin resistance in a GPR40/FFAR1 independent manner

Body weight progression was monitored during the Tonalin ${ }^{\circledR}$ application and the impact of GPR40/FFAR1 was examined (Fig. 1A). The body weight before supplementation period was: $19.5 \pm 0.7 \mathrm{~g}$ (WT, vehicle) vs. $20.8 \pm 0.9 \mathrm{~g}$ (WT, CLA), and $23.3 \pm 1.5 \mathrm{~g}($ Ffar $1 \%$, vehicle) vs. $22.6 \pm 0.7 \mathrm{~g}\left(\mathrm{Ffar}^{1 \%}\right.$, CLA $)$. Within the first week of CLA administration, body weight of WT and $\mathrm{Ffar} 1 \%^{\%}$ mice dropped by $10 \%$ and the reduced body weight was maintained over the whole feeding period (body weight at day 29 of supplementation: $21.6 \pm 0.4 \mathrm{~g}$ (WT, vehicle) vs. $18.7 \pm 0.7 \mathrm{~g}$ (WT, CLA), and $24.8 \pm 1.2 \mathrm{~g}($ Ffar $1 \%$, vehicle $)$ vs. $21.2 \pm 1.7 \mathrm{~g}($ Ffar $1 \%$, CLA $)$ ). That the method of application was not responsible for this effect is suggested by the gain in body weight of mice which were fed with sunflower oil by gavage. Furthermore, food intake was not different between the groups (data not shown). These results indicate that the reduction in body weight occurred independently of GPR40/FFAR1.

Chronic CLA ingestion did not significantly affect glucose tolerance in WT mice. However, blood glucose levels of $\mathrm{Ffar}^{-1}$ mice increased to $30 \%$ higher concentrations than that of WT mice, which reached significance by calculating areas under the curves (AUC) (Fig. 1B, C). Surprisingly, regardless of the genotype, all mice fed with CLAs developed pronounced 
Fig. 2. GPR40/FFAR1 deficiency protected from CLAs-induced triglyceride accumulation in liver of Ffar $1 \%$ mice. (A) Hepatic concentration of $c 9, t 11$ and $t 10, c 12$-CLA isomer and (B) liver triglyceride content expressed as mean+SEM of $n=3-5 /$ group. (C) TNF- $\alpha$ mRNA levels relative to the house keeping gene in hepatic tissue are expressed as mean+SEM ( $n=4-5$ /group). Significance between corresponding groups are ${ }^{*} P<0.05,{ }^{*} P<0.005,{ }^{* * *} P<0.001$. c9,t11-, cis-9, trans-11; CLAs, conjugated linoleic acids; Ffar $1 \%$, GPR40/FFAR1 knockout mice; t10,c12-, trans-10,cis-12; Tbp, TATA-binding protein; TNF- $\alpha$, tumor necrosis factor alpha; WT, wild-type.

insulin resistance (Fig. 1D). Thus, despite the development of insulin resistance glucose homeostasis was most efficiently maintained in WT mice.

GPR40/FFAR1 deficiency prevented CLAstimulated triglyceride accumulation in liver

GPR40/FFAR1 deficiency affected neither the hepatic CLA content in vehicle fed mice nor the dramatic accumulation of CLAs after chronic Tonalin ${ }^{\circledR}$ ingestion (Fig. 2A). Notably, the concentration of the $c 9, t 11$-CLA isomer was 3 -fold higher that of the $t 10, c 12$ CLA isomer in vehicle fed mice and this difference remained significant after CLA

A

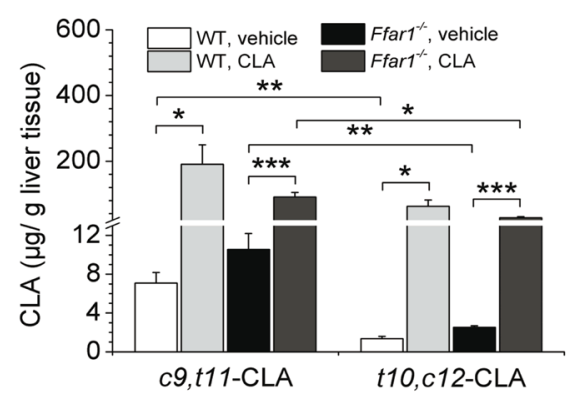

B

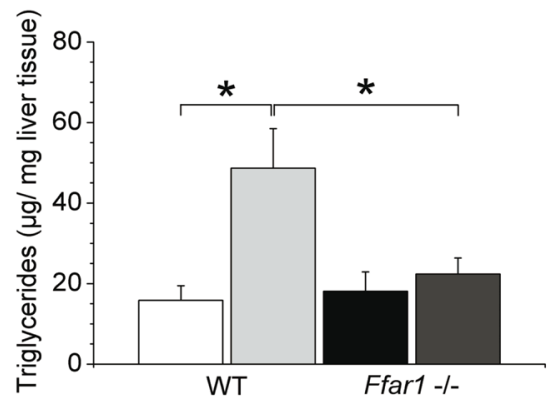

C

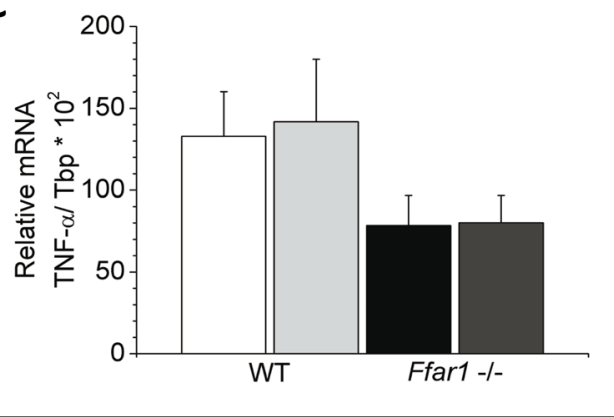

ingestion although Tonalin ${ }^{\circledR}$ contains both isomers in equal amount. Despite the identical accumulation of CLAs, hepatic triglyceride content was significantly increased only in WT but not in Ffar $^{\%}$ mice (Fig. 2B). This increase of liver triglycerides was not accompanied by increased inflammation (Fig. 2C). Besides, we did not detect any significant changes $(P>0.05)$ in plasma concentration of the proinflammatory cytokines IL1- $\beta$ (WT, vehicle vs. CLA: $291.0 \pm 55.7$ vs. $205.1 \pm 45.3 \mathrm{pg} / \mathrm{mL}$; Ffar1 $\%$, vehicle vs. CLA: $300.4 \pm 63.3$ vs. $291.0 \pm 89.8$ $\mathrm{pg} / \mathrm{mL}$ ), IL-6 (WT, vehicle vs. CLA: $4.2 \pm 0.8$ vs. $10.0 \pm 4.1 \mathrm{pg} / \mathrm{mL} ;$ Ffar $1 \%$, vehicle vs. CLA: $4.4 \pm 0.8$ vs. $8.7 \pm 4.8 \mathrm{pg} / \mathrm{mL}$ ), and TNF- $\alpha$ (WT, vehicle vs. CLA: $383.0 \pm 62.9 v s .427 .1 \pm 37.2 \mathrm{pg} /$ $\mathrm{mL}$; Ffar $1 \%$, vehicle vs. CLA: $537.8 \pm 113.8$ vs. $444.7 \pm 40.5 \mathrm{pg} / \mathrm{mL}$ ). When expression of GPR40/ FFAR1 was examined we failed to detect receptor expression in mouse liver while significant $(P<0.001)$ amounts of GPR40/FFAR1 mRNA were detectable in an insulin-secreting mouse cell line used as positive control (Fig. 3A, B). These observations suggest that GPR40/FFAR1 activity indirectly supports liver triglyceride accumulation.

\section{GPR40/FFAR1 deficiency increased neuronal inflammation and induced brain insulin} resistance

Inflammation and insulin resistance of the brain impact on peripheral glucose homeostasis and regulate body energy repartition. Therefore, the accumulation of CLAs in brain and their effects on the inflammation marker TNF- $\alpha$ and brain insulin sensitivity was examined in WT and Ffar $1 \%$ mice. In vehicle fed WT and $\mathrm{Ffarl}^{\%}$ mice the CLA content of whole brain homogenates was identical and the concentration of the $c 9, t 11$-CLA isomer was 3 -fold higher than that of the t10,c12-CLA isomer (Fig. $4 \mathrm{~A}$, white and black columns). 
Fig. 3. Detection of GPR40/FFAR1 mRNA levels in liver, Min6 and primary astrocyte cultures of wild-type mice. (A-C) Representative accumulation of PCR product for mFfar1 and the house keeping gene (mRps13) with (solid line) and without (dashed line) cDNA synthesis in (A) liver, (B) Min6 cells and (C) isolated mouse astrocytes. Note the accumulation of a specific PCR product for Ffar1 in Min6 cells used as positive control. arb. unit, arbitrary unit; mFfar1, murine Ffar1 gene; mRps13, murine ribosomal protein S13 gene; Min6, pancreatic beta cell line Min6.
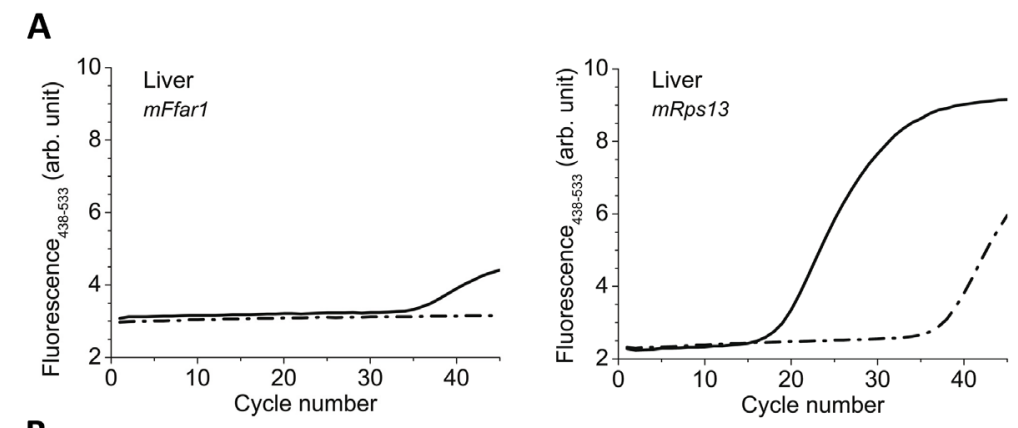

B
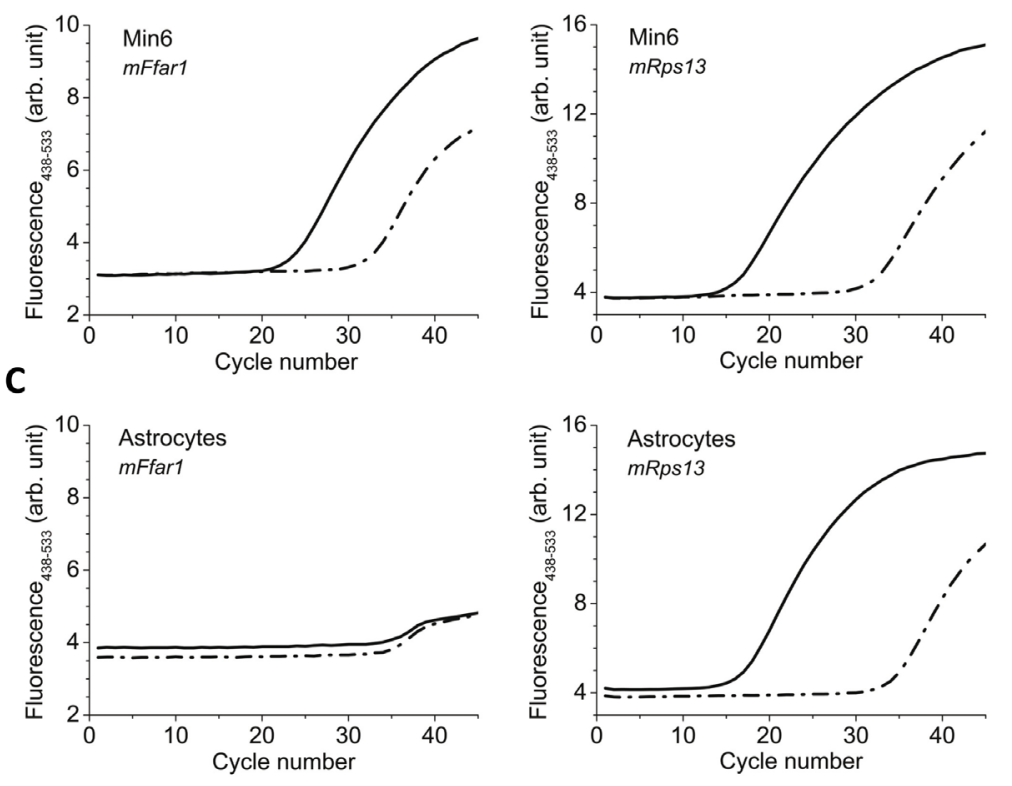

Irrespective of the genotype, after chronic Tonalin ${ }^{\circledR}$ ingestion, the difference in concentration between the isomers persisted with a 4-fold increase of the $c 9, t 11$-CLA isomer up to 14 $\mu \mathrm{g} / \mathrm{g}$ brain tissue, and a 3 -fold increase of the t10,c12-CLA up to $3 \mu \mathrm{g} / \mathrm{g}$ brain tissue (Fig. $4 \mathrm{~A}$ ). Although the accumulation of CLA isomers was identical between the genotypes, the mRNA levels of the inflammation marker TNF- $\alpha$ were significantly higher and coincided with reduced insulin sensitivity of the brain in chronically CLA-treated $\mathrm{Ffar}^{-1}$ mice compared to WT mice and vehicle mice fed regular chow diet (Fig. 4B-D). Expression analysis of Ffar1 mRNA revealed no detectable levels in mouse brain (data not shown) indicating that GPR40 / FFAR1 indirectly, through organ crosstalk, protected the brain from inflammation and insulin resistance induced by CLAs.

That CLA isomers induce inflammation is further suggested by the increase in mRNA of TNF- $\alpha$ and $I L-6$ in astrocyte cultures of WT mice (Fig. 5A and B). This effect is not mediated by GPR40/FFAR1 as it persisted in the presence of the GPR40/FFAR1 inhibitor TUG-761 (Fig. 5A and B). That the conjugated double bond system accounts for the inflammatory response is suggested by exposing primary murine astrocytes to $100 \mu \mathrm{M}$ alpha-linoleic acid $(\alpha$-LA) (as well as co-treatment of $\alpha$-LA with CLA-isomers). No significant increase of TNF- $\alpha$ and $I L-6$ gene expression was detected with $\alpha$-LA alone, whereas additional treatment with both CLA-isomers increased these parameters (Fig. 5A and B). In addition, Ffar1 mRNA was also not detectable in primary murine astrocytes (Fig. 3C).

These observations suggest that oral ingestion of Tonalin ${ }^{\circledR}$ lead to an accumulation of CLAs in brain cells, where they induce inflammation and insulin resistance. GPR40/FFAR1 counteracts the two latter effects. 
Fig. 4. GPR40/FFAR1 deficiency augmented local inflammation and insulin resistance in the brain of Ffar $1^{\%}$ mice after chronic CLAs ingestion. (A) Accumulation of $c 9, t 11$ - and $t 10, c 12-C L A$ isomer in brain tissue. (B) TNF- $\alpha$ mRNA levels relative to the house keeping gene in hypothalamus and whole brain is expressed as mean+SEM $(n=7-10)$. (C) ECoG estimated analysis of power spectral density of theta $(4-8 \mathrm{~Hz})$ and alpha $(8-12 \mathrm{~Hz})$ frequencies after i.c.v. injection of insulin. Cortical activity of WT and Ffar $1 \%$ mice after i.c.v. injection of insulin is expressed relative to the cortical activity of i.c.v. control injected mice (set to zero). Inserts illustrate the quantification of the averaged 120 min measurement period. Data are given as mean of $n=3-5$ / group. Significance between corresponding groups are ${ }^{*} P<0.05,{ }^{* *} P<0.005,{ }^{* * *} P<0.001$. "Different from CLA-fed WT mice, $P<0.05$; \#\#Different from CLA-fed WT mice, $P<0.005$; and i.c.v. insulin to control within genotype: $\cdots P<0.001$. $c 9, t 11$-, cis-9, trans-11; CLAs, conjugated linoleic acids; ECoG, electrocorticography; Ffar1\%, GPR40/FFAR1 knockout mice; GAPDH, glyceraldehyde-3-phosphate dehydrogenase; i.c.v., intracerebroventricular; t10,c12-, trans-10,cis-12; TNF- $\alpha$, tumor necrosis factor alpha; WT, wild-type.

\section{Discussion}

Apart from CLA-induced stimulation of insulin secretion through the direct activation of beta-cell specific GPR40/FFAR1 this study now gives evidence that GPR40/FFAR1 activation protects from adverse effects of CLA accumulation in brain. By the use of GPR40/FFAR1 knockout mice it became apparent that CLAs are able to induce local inflammation and concomitantly insulin resistance in the brain. That CLAs directly induce local inflammation in brain was further corroborated in vitro using isolated primary mouse astrocytes.

The protective effect of GPR40/FFAR1 on CLA-induced changes in the brain is most probably indirectly exerted through organ crosstalk as we were unable to detect

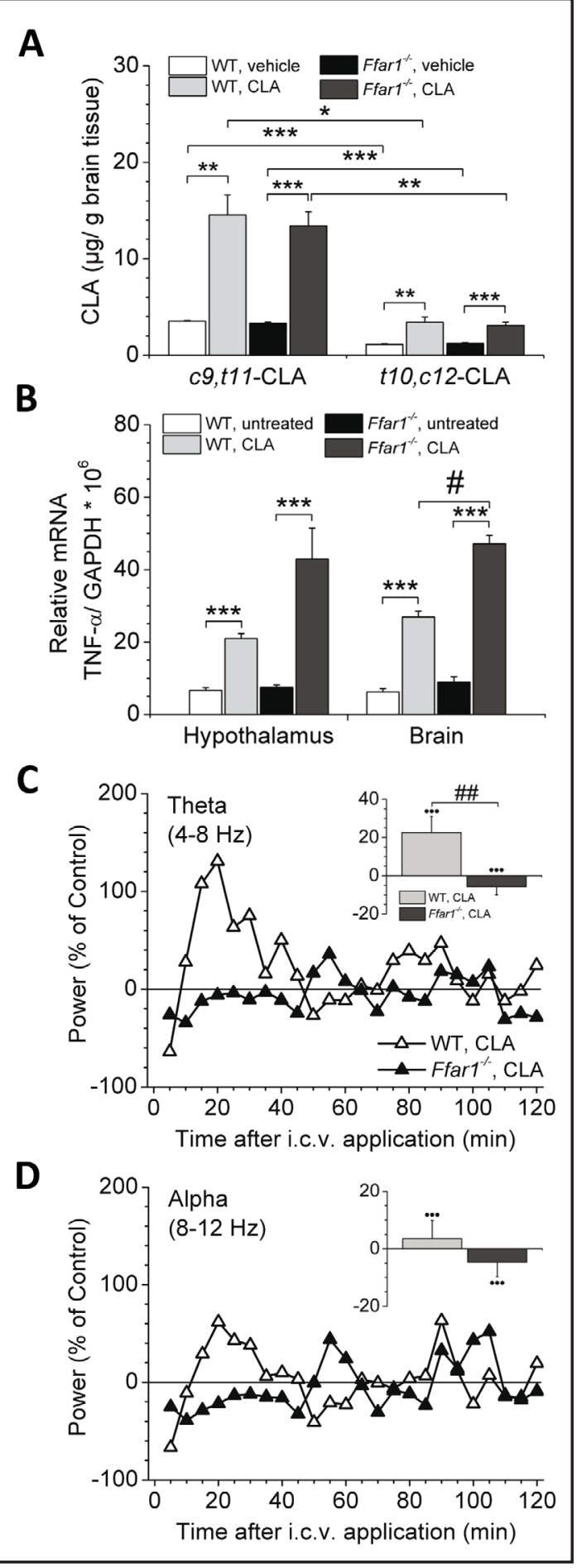

mRNA levels of Ffar1 in mouse brain by qRT-PCR. In a recent study, however, using in situ hybridization GPR40/FFAR1-specific signals were found in restricted mouse brain areas [12]. Recently, we described a direct protective effect of GPR40/FFAR1 agonists on betacell death [26]. An indirect effect of GPR40/FFAR1 on neuronal inflammation and insulin resistance induced by CLA accumulation may come from CLA-induced GPR40/FFAR1dependent stimulation of insulin and GLP-1 secretion [7, 10]. Indeed, GLP-1 has been found to be neuroprotective and could therefore limit local inflammation induced by CLAs in WT mice [27]. Furthermore, increasing evidence suggests that insulin exerts direct effects on 
Fig. 5. CLAs induced low grade inflammation in primary murine astrocyte cultures. (A) TNF- $\alpha$ and (B) IL-6 mRNA levels were assessed in primary murine astrocyte cultures of WT mice under control culture conditions or after treatment with $c 9, t 11$ - and t10,c12-CLA isomer, $100 \mu \mathrm{mol} / \mathrm{L}$ alpha-linoleic acid $(\alpha-\mathrm{LA})$ or in the presence of TUG-761, $10 \mu \mathrm{mol} / \mathrm{L}$, as indicated. Data are mean+SEM ( $n=6-10 /$ group). *Different from control, $P<0.05$; **different from control, $P<0.005$; \#\#different from TUG-761, $P<0.005$; \#\#\#different from TUG-761, $P<0.001$; $\bullet$ difference between $c 9, t 11$ - and $t 10, c 12$-CLA within $\alpha$-LA group, $P<0.05$; • different from $\alpha$-LA, $P<0.005$; $\cdot{ }^{-\bullet}$ different from $\alpha$-LA, $P<0.001$. c9,t11-, cis-9, trans-11; $\alpha$-LA, alphalinoleic acid; GAPDH, glyceraldehyde-3-phosphate dehydrogenase; IL-6, interleukin 6; t10,c12-, trans10,cis-12; TNF- $\alpha$, tumor necrosis factor alpha; TUG761, specific inhibitor of GPR40/FFAR1.

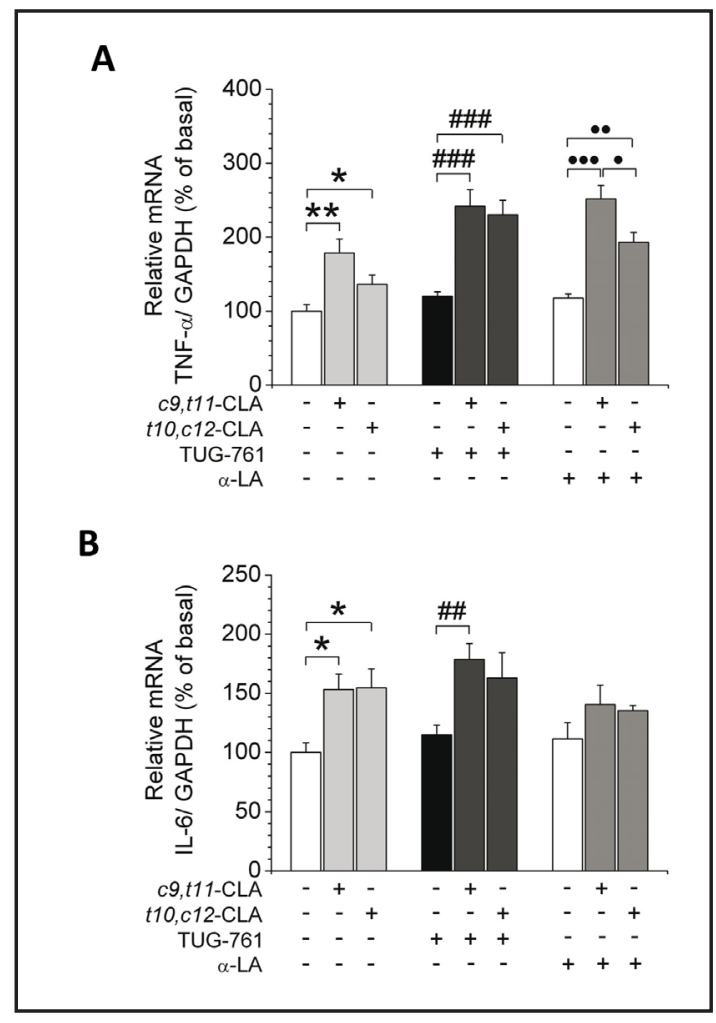

brain function, and this effect may have an impact on whole body glucose homeostasis [28, 29]. Possible direct effects of CLAs mediated by brain GPR40/FFAR1 receptors need to be explored in humans and macaques where the receptor is abundantly expressed [13-15].

Although CLAs locally induced low-grade inflammation in brain, plasma concentrations of IL-6, TNF- $\alpha$ and IL1- $\beta$ remained unchanged. In accordance, in a study of Parra et al. no impaired inflammatory status could be detected in mice treated with moderate doses of CLAs [30]. However, CLAs induced inflammation in adipose tissue and this has been associated with insulin resistance and fat cell apoptosis [31,32]. Liver inflammation remained undetectable. This implies that the tissue-specific changes of inflammation marker remain local and this could explain the partly opposing effects of CLAs observed in distinct tissues.

The finding that both CLA-isomers increased TNF- $\alpha$ and $I L-6$ mRNA in primary astrocyte cultures indicate that astrocytes may contribute to neuronal inflammation as Ffar1 mRNA was not detectable, and the antagonist TUG-761 did not inhibit CLA-induced cytokine production. However, this effect is independent of GPR40/FFAR1 as corroborated with the antagonist TUG-761 [26]. Indeed, astrocytes have been found to contribute to the local immune response within the brain through the production of both pro- and anti-inflammatory cytokines and chemokines [33]. Astrocytes, upon producing IL-6, affect neurogenesis [34, 35]. Recently, we published that mice deficient of TLR2 and 4 express lower levels of $I L-6$ mRNA in astrocytes and this impacts on cortical activity and physical behavior [36]. Furthermore, astrocytes have a role in brain fatty acid metabolism $[37,38]$. They produce docosahexaenoic acid $(22: 6 n-3)$ and arachidonic acid (20:4n-6) and are involved in the metabolism of highly unsaturated n-3 and n- 6 fatty acids. In isolated astrocytes from rat's cerebellum Fa et al. investigated the ability to take up the two CLA isomers and to degrade them into shorter fatty acids [17]. An efficient peroxisomal $\beta$-oxidation of predominantly the $t 10, c 12$-CLA isomer and an inhibition in the elongation step of this CLA isomer was found, demonstrating the ability of the brain to incorporate CLAs and to metabolize them in situ. The more efficient peroxismal $\beta$-oxidation of predominantly the t10,c12-CLA isomer might further account for the 3 -fold higher concentration of the $c 9, t 11-C L A$ isomer than that of the $t 10, c 12-C L A$ isomer, which we found both in whole brain homogenates and in liver tissue. 


\section{Cellular Physiology Cell Physiol Biochem 2015;35:2272-2284 \begin{tabular}{ll|l} 
DOI: 10.1159/000374031 & $\begin{array}{l}\text { O 2015 S. Karger AG, Basel } \\
\text { www.karger.com/cpb }\end{array}$ \\
\hline
\end{tabular} \\ Sartorius et al.: FFAR1-Mediated CLA Effects}

Although a direct application of CLAs into the cerebrospinal fluid decreased appetiteregulating neuropeptides [19], CLA incorporation into brain lipids by in vivo feeding does not correlate with changes in appetite-regulating neuropeptides and reductions in food intake [39]. We observed no change in food intake (data not shown) and in mRNA levels of $N P Y$ during CLA feeding (data not shown). These findings make it unlikely that the reduction in body weight is a consequence of altered neuronal regulation of food intake. Indeed, a reduction of body weight after CLA ingestion was not observed in all studies [40, 41]. It is noteworthy that Tonalin ${ }^{\circledR}$ is used as nutrient additive to build up muscle mass in humans, and exercise is one of the regulatory parameters to prevent hepatic steatosis and adiposity. The consequence of additional exercise on CLA-induced hepatic steatosis was not part of our experimental design, but further studies should include endurance exercise.

That CLAs exert effects in brain and affect neuronal function is further supported by the fact that lately, a negative correlation was found between CLA and Alzheimer's disease [42]. In a human neuroblastoma cell line, CLA-isomers decreased tau phosphorylation and showed neuroprotective effects against $\beta$-amyloid peptides through a specific inhibition of the calcium-dependent cysteine protease $\mu$-calpain. Emerging evidence has indicated that altered neurogenesis in the adult hippocampus represents an early critical event in the context of Alzheimer's disease [43].

In contrast to the brain, CLA accumulation in liver of WT mice was not accompanied by an increase in local inflammation markers, which is different to HFD-driven fatty liver with increased hepatic inflammation. GPR40/FFAR1 deficiency protected against CLA-induced accumulation of hepatic triglycerides. The reduction in hepatic fat deposition in $\mathrm{Ffar}^{1} \%$ mice does not seem to be mediated by a direct activation of GPR40/FFAR1 as receptor expression was not detectable in liver tissue. The most plausible link between a reduction in liver fat storage and GPR40/FFAR1 deficiency might be the lack of CLA-induced augmentation of insulin secretion. Indeed, CLAs directly stimulate insulin secretion through GPR40/FFAR1 [7]. As a consequence, insulin resistance is most efficiently compensated in the presence of GPR40/FFAR1. Thus, although CLA-induced stimulation of GPR40/FFAR1 is beneficial for the maintenance of glucose tolerance, insulin hypersecretion mediated by GPR40/FFAR1 may contribute to the development of fatty liver. That insulin contributes to CLA-induced fatty liver has been proposed previously [44]. Of note, a previous study using the same mouse model described a reduced accumulation of triglycerides in Ffar $1 \%$ mice fed a HFD [20]. In our study, young mice were fed with chow diet and approximately ingested $50 \mathrm{~kJ} /$ day. Supplementation with CLAs increased the daily ingested energy by $1-2 \%$. Therefore, an exaggerated energy intake does not explain the development of insulin resistance and the increase in liver triglycerides after Tonalin ${ }^{\circledR}$ treatment. CLAs probably increase fat deposit in liver as they reduce energy uptake into adipocytes [45]. Indeed, the animals were fed with chow diet and food intake between vehicle and CLA-treated animals was not different.

In summary, chronic ingestion of CLAs induces insulin resistance and local inflammation in the brain and this associate with local insulin resistance of the brain in $F f a r 1 \%$ mice. The

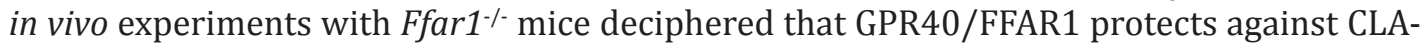
induced brain inflammation and insulin resistance, although the expression of functional receptors accentuated liver steatosis. Taking into account our previous finding that CLAs stimulate insulin secretion through GPR40/FFAR1 and the present study which gives evidence that CLAs may induce brain inflammation and insulin resistance of the brain, CLAs should be reevaluated and not considered as safe food additives but as pharmacological drugs.

\section{Abbreviations}

$\alpha$-LA (alpha-linoleic acid); c9,t11 (cis-9,trans-11); CLAs (conjugated linoleic acids); ECoG (electrocorticography); FFAR1 (free fatty acid receptor 1); Ffar1 (free fatty acid receptor 1 gene); Gapdh (glyceraldehyde 3-phosphate dehydrogenase); GPR40 (G-protein 


\begin{tabular}{|c|c|c|}
\hline Cellular Physiology & Cell Physiol Biochem 2015;35:2272-2284 & \\
\hline and Biochemistry & $\begin{array}{l}\text { DOI: 10.1159/000374031 } \\
\text { Published online: April 13, } 2015\end{array}$ & $\begin{array}{l}\text { O } 2015 \text { S. Karger AG, Basel } \\
\text { www.karger.com/cpb }\end{array}$ \\
\hline
\end{tabular}

coupled orphan receptor 40, free fatty acid receptor 1); GTT (glucose tolerance test); HFD (high fat diet); i.c.v. (intracerebroventricular); IL-6 (interleukin 6); i.p. (intraperitoneal); SCD1 (stearoyl-CoA desaturase-1); t10,c12 (trans-10,cis-12); TNF- $\alpha$ (tumor necrosis factor alpha); WT (wild type); qRT-PCR (semiquantitative reverse transcription-polymerase chain reaction).

\section{Acknowledgments}

We gratefully acknowledge the technical assistance of Andrea Janessa, Dept. Int. Med. IV, Univ. of Tuebingen, Felicitas Piossek, Dept. Int. Med. IV, Univ. of Tuebingen, Elisabeth Metzinger, Dept. Int. Med. IV, Univ. of Tuebingen, Dorothea Neuscheler, Dept. Int. Med. IV, Univ. of Tuebingen, and Mareike Walenta, Dept. Int. Med. IV, Univ. of Tuebingen. TUG761 was kindly provided by Trond Ulven (Southern University of Denmark, Denmark). We further thank Christiane Fuchs, Institute of Computational Biology, Helmholtz Center Munich, for statistical support. This study was supported by grants from the German Diabetes Association (DDG), the German Federal Ministry of Education and Research (BMBF, DLR01GI0925) to the German Center for Diabetes Research (DZD e.V.). MP is member of the DFG funded international graduate school (GRK1302). We further acknowledge support by Deutsche Forschungsgemeinschaft and Open Access Publishing Fund of University of Tübingen.

T.S. and S.U. designed the study; A.P., C.W., E.K. and H.-U.H. contributed to the conception and design of the experiments; T.S. and A.D. fed and weighed the mice; T.S. performed glucose and insulin tolerance testing, all functional brain experiments, and isolated, cultured and examined primary murine astrocytes; A.P. and P.L. performed the analysis of tissue CLA isomers and triglycerides; T.S., M.P., A.D. and C.W. performed gene expression analysis; T.S., A.P., C.W. and M.P. analyzed data; T.S. and S.U. created the figures and drafted the manuscript; and T.S. had primary responsibility for the final content. All authors revised the manuscript critically for important intellectual content. All authors read and approved the final version of the manuscript.

\section{Disclosure Statement}

The authors declare that there are no conflicts of interest.

\section{References}

1 Park Y, Storkson JM, Albright KJ, Liu W, Pariza MW: Evidence that the trans-10,cis-12 isomer of conjugated linoleic acid induces body composition changes in mice. Lipids 1999;34:235-241.

2 Whigham LD, Watras AC, Schoeller DA: Efficacy of conjugated linoleic acid for reducing fat mass: a metaanalysis in humans. Am J Clin Nutr 2007;85:1203-1211.

3 Tsuboyama-Kasaoka N, Takahashi M, Tanemura K, Kim HJ, Tange T, Okuyama H, Kasai M, Ikemoto S, Ezaki O: Conjugated linoleic acid supplementation reduces adipose tissue by apoptosis and develops lipodystrophy in mice. Diabetes 2000;49:1534-1542.

4 Choi Y, Park Y, Pariza MW, Ntambi JM: Regulation of stearoyl-CoA desaturase activity by the trans-10,cis-12 isomer of conjugated linoleic acid in HepG2 cells. Biochem Biophys Res Commun 2001;284:689-693.

5 Peter A, Weigert C, Staiger H, Rittig K, Cegan A, Lutz P, Machicao F, Haring HU, Schleicher E: Induction of stearoyl-CoA desaturase protects human arterial endothelial cells against lipotoxicity. Am J Physiol Endocrinol Metab 2008;295:E339-E349.

6 Hargrave KM, Azain MJ, Kachman SD, Miner JL: Conjugated linoleic acid does not improve insulin tolerance in mice. Obes Res 2003;11:1104-1115. 


\section{Cellular Physiology Cell Physiol Biochem 2015;35:2272-2284 \begin{tabular}{l|l} 
DOI: 10.1159/000374031 & $\begin{array}{l}\text { (c) } 2015 \text { S. Karger AG, Basel } \\
\text { www.karger.com/cpb }\end{array}$ \\
\hline
\end{tabular}}

Sartorius et al.: FFAR1-Mediated CLA Effects

7 Schmidt J, Liebscher K, Merten N, Grundmann M, Mielenz M, Sauerwein H, Christiansen E, Due-Hansen ME, Ulven T, Ullrich S, Gomeza J, Drewke C, Kostenis E: Conjugated linoleic acids mediate insulin release through islet G protein coupled receptor FFA1/GPR40. J Biol Chem 2011;286:11890-11894.

8 Briscoe CP, Tadayyon M, Andrews JL, Benson WG, Chambers JK, Eilert MM, Ellis C, Elshourbagy NA, Goetz AS, Minnick DT, Murdock PR, Sauls HR Jr, Shabon U, Spinage LD, Strum JC, Szekeres PG, Tan KB, Way JM, Ignar DM, Wilson S, Muir AI: The orphan G protein-coupled receptor GPR40 is activated by medium and long chain fatty acids. J Biol Chem 2003;278:11303-11311.

9 Itoh Y, Kawamata Y, Harada M, Kobayashi M, Fujii R, Fukusumi S, Ogi K, Hosoya M, Tanaka Y, Uejima H, Tanaka H, Maruyama M, Satoh R, Okubo S, Kizawa H, Komatsu H, Matsumura F, Noguchi Y, Shinohara T, Hinuma S, Fujisawa Y, Fujino M: Free fatty acids regulate insulin secretion from pancreatic beta cells through GPR40. Nature 2003;422:173-176.

10 Edfalk S, Steneberg P, Edlund H: Gpr40 is expressed in enteroendocrine cells and mediates free fatty acid stimulation of incretin secretion. Diabetes 2008;57:2280-2287.

11 Teutsch CA, Panse M, Grundmann M, Kaiser G, Kostenis E, Haring HU, Ullrich S: Detection of free fatty acid receptor 1 expression: the critical role of negative and positive controls. Diabetologia 2014;57:776-780.

12 Zamarbide M, Etayo-Labiano I, Ricobaraza A, Martinez-Pinilla E, Aymerich MS, Luis LJ, Perez-Mediavilla A, Franco R: GPR40 activation leads to CREB and ERK phosphorylation in primary cultures of neurons from the mouse CNS and in human neuroblastoma cells. Hippocampus 2014;24:733-739.

13 Ma D, Tao B, Warashina S, Kotani S, Lu L, Kaplamadzhiev DB, Mori Y, Tonchev AB, Yamashima T: Expression of free fatty acid receptor GPR40 in the central nervous system of adult monkeys. Neurosci Res 2007;58:394-401.

14 Boneva NB, Kikuchi M, Minabe Y, Yamashima T: Neuroprotective and ameliorative actions of polyunsaturated fatty acids against neuronal diseases: implication of fatty acid-binding proteins (FABP) and G protein-coupled receptor 40 (GPR40) in adult neurogenesis. J Pharmacol Sci 2011;116:163-172.

15 Yamashima T: A putative link of PUFA, GPR40 and adult-born hippocampal neurons for memory. Prog Neurobiol 2008;84:105-115.

16 Alasnier C, Berdeaux O, Chardigny JM, Sebedio JL: Fatty acid composition and conjugated linoleic acid content of different tissues in rats fed individual conjugated linoleic acid isomers given as triacylglycerols small star, filled. J Nutr Biochem 2002;13:337-345.

17 Fa M, Diana A, Carta G, Cordeddu L, Melis MP, Murru E, Sogos V, Banni S: Incorporation and metabolism of c9,t11 and t10,c12 conjugated linoleic acid (CLA) isomers in rat brain. Biochim Biophys Acta 2005;1736:61-66.

18 Lin X, Bo J, Oliver SA, Corl BA, Jacobi SK, Oliver WT, Harrell RJ, Odle J: Dietary conjugated linoleic acid alters long chain polyunsaturated fatty acid metabolism in brain and liver of neonatal pigs. J Nutr Biochem 2011;22:1047-1054.

19 Cao ZP, Wang F, Xiang XS, Cao R, Zhang WB, Gao SB: Intracerebroventricular administration of conjugated linoleic acid (CLA) inhibits food intake by decreasing gene expression of NPY and AgRP. Neurosci Lett 2007;418:217-221.

20 Steneberg P, Rubins N, Bartoov-Shifman R, Walker MD, Edlund H: The FFA receptor GPR40 links hyperinsulinemia, hepatic steatosis, and impaired glucose homeostasis in mouse. Cell Metab 2005;1:245258.

21 Poitout V, Lin DC: Modulating GPR40: therapeutic promise and potential in diabetes. Drug Discov Today 2013;18:1301-1308.

22 Lan H, Hoos LM, Liu L, Tetzloff G, Hu W, Abbondanzo, SJ, Vassileva G, Gustafson EL, Hedrick JA, Davis HR: Lack of FFAR1/GPR40 does not protect mice from high-fat diet-induced metabolic disease. Diabetes 2008;57:2999-3006.

23 Sartorius T, Ketterer C, Kullmann S, Balzer M, Rotermund C, Binder S, Hallschmid M, Machann J, Schick F, Somoza V, Preissl H, Fritsche A, Häring HU, Hennige AM: Monounsaturated fatty acids prevent the aversive effects of obesity on locomotion, brain activity, and sleep behavior. Diabetes 2012;61:1669-1679.

24 Peter A, Stefan N, Cegan A, Walenta M, Wagner S, Konigsrainer A, Konigsrainer I, Machicao F, Schick F, Häring HU, Schleicher E: Hepatic glucokinase expression is associated with lipogenesis and fatty liver in humans. J Clin Endocrinol Metab 2011;96:E1126-E1130.

25 Hamprecht B, Löffler F: Primary glial cultures as a model for studying hormone action. Methods Enzymol 1985;109:341-345. 


\section{Cellular Physiology Cell Physiol Biochem 2015;35:2272-2284 \begin{tabular}{l|l|l}
\hline DOI: 10.1159/000374031 & C 2015 S. Karger AG, Basel
\end{tabular} www.karger.com/cpb \\ Sartorius et al.: FFAR1-Mediated CLA Effects}

26 Wagner R, Kaiser G, Gerst F, Christiansen E, Due-Hansen ME, Grundmann M, Machicao F, Peter A, Kostenis E, Ulven T, Fritsche A, Häring HU, Ullrich S: Reevaluation of fatty acid receptor 1 as a drug target for the stimulation of insulin secretion in humans. Diabetes 2013;62:2106-2111.

27 During MJ, Cao L, Zuzga DS, Francis JS, Fitzsimons HL, Jiao X, Bland RJ, Klugmann M, Banks, WA, Drucker DJ, Haile CN: Glucagon-like peptide-1 receptor is involved in learning and neuroprotection. Nat Med 2003;9:1173-1179.

28 Hennige AM, Sartorius T, Lutz SZ, Tschritter O, Preissl H, Hopp S, Fritsche A, Rammensee HG, Ruth P, Haring HU: Insulin-mediated cortical activity in the slow frequency range is diminished in obese mice and promotes physical inactivity. Diabetologia 2009;52:2416-2424.

29 Tschritter O, Preissl H, Hennige AM, Sartorius T, Stingl KT, Heni M, Ketterer C, Stefan N, Machann J, Schleicher E, Fritsche A, Häring HU: High cerebral insulin sensitivity is associated with loss of body fat during lifestyle intervention. Diabetologia 2012;55:175-182.

30 Parra P, Palou A, Serra F: Moderate doses of conjugated linoleic acid reduce fat gain, maintain insulin sensitivity without impairing inflammatory adipose tissue status in mice fed a high-fat diet. Nutr Metab (Lond) 2010; 7:5.

31 Kennedy A, Overman A, Lapoint K, Hopkins R, West T, Chuang CC, Martinez K, Bell D, McIntosh M: Conjugated linoleic acid-mediated inflammation and insulin resistance in human adipocytes are attenuated by resveratrol. J Lipid Res 2009;50:225-232.

32 Poirier H, Shapiro JS, Kim RJ, Lazar MA: Nutritional supplementation with trans-10, cis-12-conjugated linoleic acid induces inflammation of white adipose tissue. Diabetes 2006;55:1634-1641.

33 Ransohoff RM, Brown MA: Innate immunity in the central nervous system. J Clin Invest 2012;122:11641171.

34 Vallieres L, Campbell IL, Gage FH, Sawchenko PE: Reduced hippocampal neurogenesis in adult transgenic mice with chronic astrocytic production of interleukin-6. J Neurosci 2002;22:486-492.

35 Kohman RA, Rhodes JS: Neurogenesis, inflammation and behavior. Brain Behav Immun 2013;27:22-32.

36 Sartorius T, Lutz SZ, Hoene M, Waak J, Peter A, Weigert C, Rammensee HG, Kahle PJ, Haring HU, Hennige AM: Toll-like receptors 2 and 4 impair insulin-mediated brain activity by interleukin- 6 and osteopontin and alter sleep architecture. FASEB J 2012;26:1799-1809.

37 Moore SA, Yoder E, Murphy S, Dutton GR, Spector AA: Astrocytes, not neurons, produce docosahexaenoic acid (22:6 omega-3) and arachidonic acid (20:4 omega-6). J Neurochem 1991;56:518-524.

38 Sprecher H: Metabolism of highly unsaturated n-3 and n-6 fatty acids. Biochim Biophys Acta 2000;1486:219-231.

39 Shelton VJ, Shelton AG, Azain MJ, Hargrave-Barnes KM: Incorporation of conjugated linoleic acid into brain lipids is not necessary for conjugated linoleic acid-induced reductions in feed intake or body fat in mice. Nutr Res 2012;32:827-836.

40 Eyjolfson V, Spriet LL, Dyck DJ: Conjugated linoleic acid improves insulin sensitivity in young, sedentary humans. Med Sci Sports Exerc 2004;36:814-820.

41 Raff M, Tholstrup T, Sejrsen K, Straarup EM, Wiinberg N: Diets rich in conjugated linoleic acid and vaccenic acid have no effect on blood pressure and isobaric arterial elasticity in healthy young men. J Nutr 2006;136:992-997.

42 Lee E, Eom JE, Kim HL, Baek KH, Jun KY, Kim HJ, Lee M, Mook-Jung I, Kwon Y: Effect of conjugated linoleic acid, mu-calpain inhibitor, on pathogenesis of Alzheimer's disease. Biochim Biophys Acta 2013;1831:709718.

43 Fuster-Matanzo A, Llorens-Martin M, Jurado-Arjona J, Avila J, Hernandez F: Tau protein and adult hippocampal neurogenesis. Front Neurosci 2012;6:104.

44 Clement L, Poirier H, Niot I, Bocher V, Guerre-Millo M, Krief S, Staels B, Besnard P: Dietary trans-10,cis-12 conjugated linoleic acid induces hyperinsulinemia and fatty liver in the mouse. J Lipid Res 2002;43:14001409.

45 Obsen T, Faergeman NJ, Chung S, Martinez K, Gobern S, Loreau O, Wabitsch M, Mandrup S, McIntosh M: Trans-10, cis-12 conjugated linoleic acid decreases de novo lipid synthesis in human adipocytes. J Nutr Biochem 2012;23:580-590. 